\title{
On the economics of decarbonization in an imperfect world
}

\author{
Ottmar Edenhofer • Carlo Carraro • \\ Jean-Charles Hourcade
}

Received: 29 June 2012 / Accepted: 10 July 2012 / Published online: 28 July 2012

(C) Springer Science+Business Media B.V. 2012

\section{Motivation for the RECIPE project}

The economics of decarbonization have become an important topic over the last decade, as many research groups have explored the costs and technologies of decarbonization. These scenarios have been widely used by institutions like the Intergovernmental Panel on Climate Change (IPCC) and many national advisory bodies across the globe. However, most of these scenarios and cost estimates have been derived under the restrictive and unrealistic assumptions that all relevant technologies are available, that all countries will participate in an international agreement to control green house gas (GHG) emissions, and that all these countries will immediately implement their GHG mitigation plans. Therefore, inertia, pathdependencies of infrastructure investments, and the impact of myopic behavior on the costs of mitigation have been widely ignored. In addition, most of the scenarios have not analyzed explicitly the design of policy instruments. The impact of rent generation and rent

Grateful acknowledgement is made for financial support provided by WWF and Allianz SE.

O. Edenhofer $(\bowtie)$

Potsdam Institute for Climate Impact Research, P.O. Box 6012 03, 14412 Potsdam, Germany

e-mail: ottmar.edenhofer@pik-potsdam.de

O. Edenhofer

Economics of Climate Change, Technische Universität Berlin, Straße des 17. Juni 145, 10623 Berlin, Germany

C. Carraro

Euro-Mediterranean Centre for Climate Change, Isola di San Giorgio Maggiore, 30124 Venice, Italy

C. Carraro

Department of Economics, University of Venice, Dorsoduro 3246, 30123 Venice, Italy

C. Carraro

Fondazione Eni Enrico Mattei (FEEM), Isola di San Giorgio Maggiore, 30124 Venice, Italy

J.-C. Hourcade

Centre International de Recherche sur 1'Environnement et le Développement (CIRED, ParisTech/ENPC

\& CNRS/EHESS), 45 bis, avenue de la Belle Gabrielle, 94736 Nogent-sur-Marne Cedex, France 
distribution was a hot topic in the fields of political economy and development economics, but this topic has not received the same attention in the climate policy sphere. In other words, second-best settings and their implications for climate policy are under-researched topics.

The RECIPE Project (Report on Energy and Climate Policy in Europe) provides a range of scenarios that no longer assume a perfect world; instead, they explore the impact of inconvenient, but realistic, constraints on mitigation costs and strategies. The purpose of these scenarios is to enhance the quality of academic researchultimately feeding more accurate information into the political debates surrounding climate change mitigation. Because the scenarios in the RECIPE project have and will continue to be used in IPCC (2011) and other assessment reports that inform the United Nations Framework Convention on Climate Change (UNFCCC) processes, its results are integrated into a broader sphere of political relevance. The role of science in decision-making has become an issue for scientific scrutiny in itself. Therefore, the guest editors of this Special Issue briefly discuss the challenges of the science-policy interface and move into exploring the role of model comparison projects within this interface, examining the specific aspects of the RECIPE project that allow a more informed political process. The main results of the RECIPE project are presented in the final section.

\section{The art of assessment making}

Integrated Assessment Models (IAMs) have become an important tool for long-term policy analysis at the global, European, and local levels. Long-term scenarios from IAMs have been central to the IPCC reports for the last 20 years; therefore, they are influential in UNFCCC negotiations. A number of other projects have also used IAMs to gather their results, including the Stern Review (Stern 2006), which used these scenarios to assess the costs of mitigation action and inaction, and the Energy Road Map of the EU (European Commission 2011). At the national level, the German Energiewende (energy transition) is an example of how model scenarios are used in the policy arena (Knopf et al. 2011).

However, the role of IAMs, as well as the role of expert knowledge in the political decision-making process has recently become more contentious and a focus of public attention. The IPCC, for example, has been criticized and accused of exaggerating the risks of climate change, recommending specific policies, and obscuring normative judgments in scientific statements. Several independent investigations of IPCC reports have shown the robustness of the results, but have not received the same media attention. The Interacademy Council, an independent body invited to review the IPCC's principles and procedures in response to the aforementioned criticisms found the IPCC's assessments to be successful, but nonetheless recommended some basic reforms to the IPCC's processes and communications procedures (IAC 2010). These recommendations have been adopted and subsequently implemented.

Nevertheless, procedures and institutional safeguards only scratch the surface of what is, in reality, a deep philosophical problem: Scientists and representatives from civil society have raised concerns that political decisions are prescribed by experts without an exposition of the available options, without an explicit explanation of criteria used for the evaluation of these options and without justifying their role in the decision-making process as advocates or experts (Pielke 2007). Therefore, some scholars have highlighted the risk of obscuring the division of labor between scientific and political decision-making (Edenhofer and Seyboth 2013; Pielke 2007). 
Policy-makers expect scientists to provide clear scientific answers to the questions they pose. However, sometimes, scientists cannot provide these answers because the knowledge is still incomplete. Moreover, the answers to controversial questions may involve moral judgments. For example, any research evaluating the long-term human response options to climate change has to make a series of value judgments, e.g. judgments regarding the choice of appropriate discount factors, equity weights, technological risks, etc. The identification of "appropriate" values cannot be the result of scientific inquiry because experts neither have the legitimacy nor a better moral judgment than ordinary citizens.

Science should hence not provide prescriptive recommendations, but should rather inform the public about the implications of various options, each with its own set of tradeoffs. Scientists should assume a role akin to that of the cartographer-exploring the entire solution space, mapping out different paths available within the solution space, and clearly marking the implied value assumptions, uncertainties, and trade-offs. Based on a transparent analysis of the solution space, policy-makers need to be prepared to make the required value judgments and choose the appropriate societal pathways (Edenhofer and Seyboth 2013; Edenhofer and Kowarsch 2012).

Modeling inter-comparison exercises are a crucial ingredient for a comprehensive exploration of the solution space. These exercises are complicated by the fact that fundamental uncertainties exist across models that impede a comprehensive exploration of the solution space, such as uncertainties about future socio-economic pathways and evaluation criteria of the different options. Both types of uncertainties are irreducible to a certain extent. However, carefully designed modeling-comparison studies can facilitate a rational debate about them. The impact of different technologies in terms of the costs, risks, and institutional requirements of the different pathways, as well as the impact of different evaluation criteria on the output of IAMs, can be made explicit using a harmonized IAM ensemble. This makes it possible to obtain some understanding of the uncertainties associated with a particular pathway. As such, model harmonization provides a systematic way of evaluating the influence of key parameters, assumptions, and value judgments on the model results. Ultimately, it provides increased transparency over the assumptions and value judgments that are associated with the models and is the foundation for enabling an informed choice of transformation pathways based on a specific and explicit set of values.

Figure 1 provides an overview of the complexity of the solution space and the broad range of options that are available for mitigating climate change. Mitigation options include the reduction of carbon dioxide $\left(\mathrm{CO}_{2}\right)$ emissions (increasing energy efficiency, increasing non-fossil fuel-based energy production, and the use of carbon capture and storage), non$\mathrm{CO}_{2}$ mitigation, $\mathrm{CO}_{2}$ removal (CDR) and solar radiation management (SRM). A challenge for the integrated assessment community will be to explore the entire solution space and to do so in an integrative way that allows a clear explanation of the costs, risks, and institutional requirements associated with the different stabilization pathways.

The IPCC's Fourth Assessment Report highlighted the insufficient understanding of lowstabilization pathways and the complexity of evaluating the whole solution space in order to inform stakeholders about the relevant strategies to control GHG emissions (IPCC 2007). The RECIPE project was designed to help filling these gaps and evaluate alternative lowstabilization pathways. The RECIPE project has a second important goal: As previously stated, IAMs have traditionally assumed a perfect world, where all technologies are available, perfect foresight exists, and global cooperation is attained. While the exploration of such a first best world is undoubtedly an important reference case, it has also contributed to the image of IAMs as optimistic and detached from the real world. The RECIPE project extends the exploration of the solution space by systematically investigating imperfect 


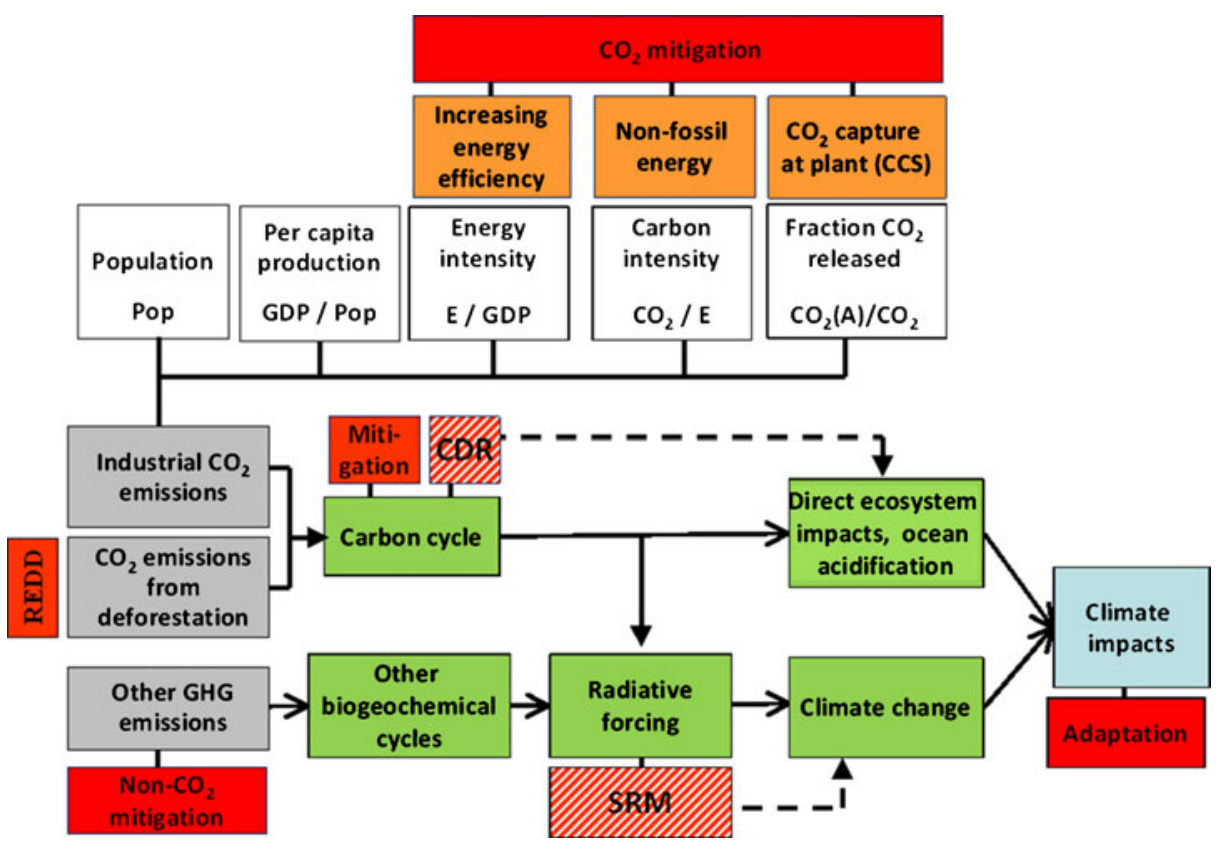

Fig. 1 Illustration of mitigation, adaptation, Solar Radiation Management (SRM) and Carbon Dioxide Removal (CDR) methods in relation to the interconnected human, socio-economic and climatic systems and with respect to mitigation and adaptation. The top part of the figure represents the Kaya identity. REDD stands for Reduced Emissions from Deforestation and forest Degradation (Edenhofer et al. 2012)

worlds with regard to the availability of crucial mitigation technologies and the impact of delayed and incomplete participation. The variations of imperfect world assumptions can be seen as explorations of uncertainty in the crucial parameters of the model. Parameter uncertainty refers to a lack of empirical knowledge, which implies uncertainty in the predictions of the course of action. These discrepancies may occur in otherwise similar models when different assumptions about the parameter values are adopted (Mastrandrea et al. 2011).

In scenarios, when crucial technologies like renewables or CCS are fixed to their baselines i.e. no additional investments on these technologies are assumed to be made, the impact on the costs of mitigation informs decision-makers about the relative importance of specific mitigation options. Likewise, the impact of delayed participation on the feasibility of stabilization targets describes the window of opportunity for negotiators and informs them about the relevance of carbon lock-ins as well as the role of expectations for low-carbon investments. These sensitivity studies expand the scope of the currently available scenarios, which provides information on first best policy options rather than on realistic ones. In other words, they allow for drawing a map of robust strategies which are viable under different assumptions about future technologies and policies.

These sensitivity studies are consistent with second-best studies usually carried out in welfare economics. In contrast to second-best scenarios, a first-best setting assumes that all market failures can be corrected. Most IAMs assume a first-best world setting. Therefore, many IAMs have been able to achieve long-term stabilization using assumptions that are rightly perceived as highly unrealistic. A second-best model calculates optimal policies 
under the condition that some market or policy constraints cannot be removed. The sensitivity studies carried out in the RECIPE project are second-best scenarios because they evaluate welfare changes under three conditions a) constraints on the availability of technologies or on the timing of policies b) constraints on the degree of countries' participation in international agreements and c) constraints on the quality of expectations that shape decision behaviors.

The RECIPE modelers not only use sensitivity studies for their uncertainty analyses but also take into account the uncertainties resulting from different modeling philosophies that represent socioeconomic and technological systems as well as value systems. There is an ongoing debate to this date about the theoretical and empirical foundation of economic models, which prevents a consensus from being reached within the scientific community according to these principles.

As several papers within this Special Issue show, more realistic assumptions-taken into account by models that represent different visions of the world might allow policy-makers to re-evaluate low-stabilization pathways. One key result of the RECIPE project is that low stabilization is no longer attainable in some scenarios under these more realistic assumptions. More generally, the institutional requirements in the areas of technology policy or international cooperation are more demanding once we acknowledge constraints that policy-makers have to deal with. For example, this means, that the costs of low stabilization increase once we accept the existence of more constraints on the availability of technologies and the degree and timing of global cooperation. This in turn raises the question of what policy packages are suitable to decrease these costs by removing some of these constraints or by inserting climate policies in a broader set of institutional reforms. By providing such new information, RECIPE might facilitate, e.g. a public debate about the diverse costs and benefits of renewable energy technologies, CCS and other negative emissions technologies.

The RECIPE scenarios have been submitted for consideration within the IPCC's Fifth Assessment Report (AR5). The IPCC, one of the first intergovernmental panels, is offering a unique laboratory to test the different conceptualizations of the scenarios. In this way, the results of this modeling inter-comparison have become part of a wider exploration of the solution space in a sample of hundreds of other scenarios. Some of these scenarios will be developed within the new scenario framework, which has been designed by the scientific community over the past few years to ensure a consistent exploration of the solution space for climate change control across the global scientific communities from the physical sciences, to climate change impacts, to possible adaptation and mitigation responses (for more details see Kriegler et al. 2012; Arnell et al. 2011; Edenhofer and Seyboth 2013; Moss et al. 2010). The RECIPE modeling comparison will therefore provide its results into a process that will be broadly relevant and consistent across the scientific disciplines related to climate change including the scientific basis, adaptation efforts and mitigation strategies.

\section{Crucial results of the RECIPE project in light of assessment-making}

This special issue contains a total of seven papers that highlight different aspects of the RECIPE project results. As a starting point, a synthesis paper presents the results of an indepth modeling comparison of the three participating integrated assessment models: WITCH, IMACLIM and REMIND. This synthesis paper is followed by three articles discussing different aspects of decarbonization: the role of technology, regional aspects of mitigation, and delayed participation to international mitigation efforts. 
Three final papers of this special issue present individual model studies and analyze features that are specific to the three models used in the RECIPE project. The paper on the IMACLIM model focuses on technological inertia in infrastructure and path dependencies, the paper on the WITCH model concentrates on technological innovation and the role of investments in research and development (R\&D), and the paper on the REMIND model analyzes the role of renewables in low-stabilization scenarios.

The synthesis paper by Luderer et al. (2011) synthesizes the results of the RECIPE project by comparing a first-best model setting with a second-best model setting. Based on the scenario results, the paper estimates the costs of stabilizing the $\mathrm{CO}_{2}$ concentration at $450 \mathrm{ppm}$ amount to $1.4 \%$ or lower in the case of full availability of technologies and immediate action. However, either a delay in climate policy or restrictions on the availability of low carbon technologies can result in a substantial increase of mitigation costs. A delay of global climate policy until 2030 would render the $450 \mathrm{ppm}$ target unachievable. It also turns out that CCS und renewable energy technologies are the most important mitigation options across all three models. The model comparison exercise further shows that low stabilization pathways require a full decarbonization of the electricity sector by the middle of the twentyfirst century, while the transport sector largely determines the total cost of the lowstabilization scenarios. The results suggest that the costs and feasibility of low stabilization scenarios for non-electric demand are key determinants of the long-term costs and achievability of low-stabilization targets. This conclusion is directly relevant to the current European debate on climate and energy policy: While the power sector is included in the European Emissions Trading Scheme, the debate on cost-effective policy instruments within the transport sector has to be continued if low-stabilization scenarios are to be achieved.

The paper by Tavoni et al. (2011) examines the role and value of technology and its evolution towards a low carbon economy. This paper analyzes the impact of the limited availability of mitigation technologies on mitigation costs and mitigation strategies. The project has shown that renewable energy technologies and CCS are crucial for the feasibility of ambitious mitigation targets. However, the availability of CCS and some renewable technologies might be limited for technical and institutional reasons. The authors argue that the particularly high value of CCS and renewables can be explained by the multi-purpose attributes of these technologies. They also show that restrictions on mature technologies can be compensated by more investments in innovation. This paper emphasizes that an exclusive focus on already existing technologies will reduce the flexibility of climate policy. This aspect is often neglected in the current policy debate.

The fate of economies dominated by rent-seeking activities is often discussed in the fields of political economy studies and development economics. However, global climate policies have somehow omitted this important aspect. Climate policy transforms resource rent into climate rent, which can be distributed across regions in various ways. Luderer et al. (2012) analyze the regional distribution of mitigation costs in a global cap-and-trade regime by examining four stylized burden-sharing schemes, ranging from convergence to equal-per-capita rights to allocation in proportion to GDP. The comparison of the three models analyzed in RECIPE shows a remarkable deviation in regional costs from the global mean. The authors decompose the effects, which determine the regional mitigation costs. They also show that the carbon price level is a dominant factor in determining the regional distribution of mitigation costs. Therefore, uncertainty about future carbon prices results in a large uncertainty about rent distribution. The political debate surrounding the management of financial transfers has already begun. This paper clearly stresses the importance of this aspect and sets a new agenda item for the economics of climate change. 
The paper by Jakob et al. (2011) explores the costs of delayed participation in international collaborative efforts for climate change mitigation. In contrast to many scientists who use an emissions gap analysis as an indicator for the urgency of action, the authors of this paper have framed their analysis as a "cost gap." The authors find that for low stabilization levels, the postponement of a global agreement until 2020 raises the global mitigation costs by at least about half and a delay until 2030 renders ambitious climate targets infeasible as the costs of mitigation becomes very high. The urgency of action for international climate policy is not driven by an emissions gap, but by an increase in mitigation costs due to a lockin into carbon intensive infrastructure, differences in global carbon prices, and the challenge of committing governments to policies. The paper also analyzes the implication of immediate action by a group of countries, while others delay action until 2020. The authors find that the benefits of early action due to avoidance of carbon lock-ins tends to outweigh the costs that arise from higher overall GHG reduction commitments and from losses of competitiveness in international markets.

Waisman et al. (2012) use a hybrid general equilibrium model to analyze the interplay between technological inertia in infrastructure and myopic investment decisions. This study strongly focuses on the transport sector, which is crucial for long-term infrastructure investments. The authors argue that public investments in low-carbon infrastructure are beneficial when there is an underutilization of the capital stock and unemployment plagues economies due to financial crisis. This insight could be important in a situation where fiscal packages are designed beyond the traditional Keynesian recipe of investments, which has previously focused on houses and roads without considering their energy and carbon content.

The WITCH model is unique in its endogenous representation of various processes related to technological innovation. De Cian et al. (2011) use this model to evaluate the innovation and diffusion of technologies under different assumptions based on the timing of climate policies and expectations about future climate policies. The authors find that climate policy results in a substantial up-scaling of R\&D efforts. These R\&D expenditures depend strongly on the stringency of the climate target, and the credibility of climate policies. Moreover, the authors find that the adopted climate policy architecture has a strong effect on the distribution of innovation efforts across countries.

The last paper by Bauer et al. (2011) examines the role of renewable technologies. It asks whether renewables can serve as a near-term option when a reliable carbon price cannot be implemented. Within this second-best context, short-term support schemes of investments in renewables could be an intermediate step to a more comprehensive climate policy. The authors show that technology policies that promote renewables can decrease mitigation costs substantially when carbon pricing is suboptimal. This result might come as a surprise because renewable policies could be considered vulnerable to the rebound-effect (Kalkuhl et al. 2012). However, investing in renewables avoids lock-ins into carbon-intensive infrastructure, which reduces mitigation costs and future technology costs by accelerating technological innovation. An important lesson learned from this analysis is that technology policies only work when market agents expect an international climate agreement.

The stakeholders and scientists involved in the RECIPE project have learned that the science-policy interaction does not start when policy-makers have agreed to emissions reduction targets and it does not end when scientists have explored the means to achieve them. Both sides need to be involved in a social learning process where the goals are revalued and the indirect consequences are revealed by science. The RECIPE project can be considered such a learning process. 


\section{References}

Arnell N, Kram T, Carter T, Ebi K, Edmonds J, Hallegatte S, Kriegler E, Mathur R, O’Neill B, Riahi K, Winkler H, van Vuuren D, Zwickel T (2011) A framework for a new generation of socioeconomic scenarios for climate change impact, adaptation, vulnerability, and mitigation research. http://www.isp. ucar.edu/socio-economic-pathways. Accessed 1 June 2012

Bauer N, Baumstark L, Leimbach M (2011) The REMIND-R model: the role of renewables in the low-carbon transformation - first-best vs. second-best worlds. Clim Chang. doi:10.1007/s10584-011-0129-2

De Cian E, Bosetti V, Tavoni M (2011) Technology innovation and diffusion in "less than ideal" climate policies: an assessment with the WITCH model. Clim Chang. doi:10.1007/s10584-011-0320-5

Edenhofer O, Kowarsch M (2012) A pragmatist approach to the science-policy interface. Working Paper

Edenhofer O, Seyboth K (2013) Intergovernmental panel on climate change. In: Shogren JF (ed) Encyclopedia of energy, natural resource and environmental economics, accepted. Elsevier, San Diego

Edenhofer O, Pichs-Madruga R, Sokona Y, Field C, Barros V, Stocker TF, Dahe Q, Minx J, Mach K, Plattner GK, Schlömer S, Hansen G, Mastrandrea M (eds) (2012) IPCC Expert Meeting on Geoengineer in Lima Peru 20-22 June 2011 Meeting Report

European Commission (2011) Energy Roadmap 2050, SEC(2011) 1565 final. COMMISSION STAFF WORKING PAPER. http://ec.europa.eu/energy/energy2020/roadmap/doc/roadmap2050_ia_20120430_ en.pdf. Accessed 1 June 2012

IAC (2010) Climate change assessments - review of the process and procedures of the IPCC. InterAcademy Council (IAC). http://www.ipcc.ch/pdf/IAC_report/IAC\%20Report.pdf, accessed 1 June 2012

IPCC (2007) Contribution of working group III to the Fourth Assessment Report of the Intergovernmental Panel on Climate Change. In: Metz B, Davidson OR, Bosch PR, Dave R, Meyer LA (eds). Cambridge University Press, Cambridge

IPCC (2011) Renewable energy sources and climate change mitigation. Special Report of the Intergovernmental on Climate Change. In: Edenhofer O, Pichs-Madruga R, Sokona Y, Seyboth K, Matschoss P, Kadner S, Zwickel T, Eickemeier P, Hasen G, Schloemer S, von Stechow C (eds). Cambridge University Press, Cambridge

Jakob M, Luderer G, Steckel JC, Tavoni M, Monjon S (2011) Time to act now? Assessing the costs of delaying climate measures and benefits of early action. Clim Chang. doi:10.1007/s10584-011-0128-3

Kalkuhl M, Edenhofer O, Lessmann K (2012) Learning or lock-in: optimal technology policies to support mitigation. Resour Energ Econ 34(1):1-23

Knopf B, Kondziella H, Pahle M, Götz M, Bruckner T, Edenhofer O (2011) Scenarios for phasing out nuclear energy in Germany. Friedrich-Ebert-Stiftung

Kriegler E, O’Neill B, Hallegatte S, Kram T, Lempert R, Moss R, Wilbanks T (2012) The need for and use of socio-economic scenarios for climate change analysis: a new approach based on shared socio-economic pathways. Global Environ Chang. doi:10.1016/j.gloenvcha.2012.05.005

Luderer G, Bosetti V, Jakob M, Leimbach M, Steckel JC, Waisman H, Edenhofer O (2011) The economics of decarbonizing the energy system - results and insights from the RECIPE model intercomparison. Clim Chang. doi:10.1007/s10584-011-0105-x

Luderer G, De Cian E, Hourcade JC, Leimbach M, Waisman H, Edenhofer O (2012) On the regional distribution of mitigation costs in a global cap-and-trade regime. Clim Chang. doi:10.1007/s10584-012-0408-6

Mastrandrea MD, Mach KJ, Plattner GK, Edenhofer O, Stocker TF, Field CB, Ebi KL, Matschoss PR (2011) The IPCC AR5 guidance note on consistent treatment of uncertainties a common approach across the working groups. Clim Chang 108:675-691

Moss RH, Edmonds JA, Hibbard KA, Manning MR, Rose SK, van Vuuren DP, Carter TR, Emori S, Kainuma M, Kram T, Meehl GA, Mitchell JFB, Nakicenovic N, Riahi K, Smith SJ, Stouffer RJ, Thomson AM, Weyant JP, Wilbanks TJ (2010) The next generation of scenarios for climate change research and assessment. Nature 463: 747-756. doi:10.1038/nature08823

Pielke R (2007) The honest broker: Making sense of science in policy and politics. Cambridge University Press, Cambridge

Stern N (2006) Stern review on the economics of climate change. HM Treasury, London

Tavoni M, De Cian E, Luderer G, Steckel JC, Waisman H (2011) The value of technology and of its evolution towards a low carbon economy. Clim Chang. doi:10.1007/s10584-011-0294-3

Waisman H, Guivarch C, Grazi F, Hourcade JC (2012) The IMACLIM-R model: infrastructures, technical inertia and the costs of low carbon futures under imperfect foresight. Clim Chang. doi:10.1007/s10584-011-0387-z 